\title{
A Full Hydrodynamic Modelling of 2D Breaker Bar Development
}

\author{
Jacobsen, Niels Gjøl; Fredsøe, Jørgen
}

Published in:

7. International Symposium on Coastal Engineering and Science of Coastal Sediment Processes

Publication date:

2011

Document Version

Early version, also known as pre-print

Link back to DTU Orbit

Citation (APA):

Jacobsen, N. G., \& Fredsøe, J. (2011). A Full Hydrodynamic Modelling of 2D Breaker Bar Development. In 7. International Symposium on Coastal Engineering and Science of Coastal Sediment Processes

\section{General rights}

Copyright and moral rights for the publications made accessible in the public portal are retained by the authors and/or other copyright owners and it is a condition of accessing publications that users recognise and abide by the legal requirements associated with these rights.

- Users may download and print one copy of any publication from the public portal for the purpose of private study or research.

- You may not further distribute the material or use it for any profit-making activity or commercial gain

- You may freely distribute the URL identifying the publication in the public portal

If you believe that this document breaches copyright please contact us providing details, and we will remove access to the work immediately and investigate your claim 


\title{
A FULL HYDRODYNAMIC MODELLING OF 2D BREAKER BAR DEVELOPMENT
}

\author{
NIELS GJØL JACOBSEN ${ }^{1}$, JØRGEN FREDSØE ${ }^{1}$ \\ 1. Coastal, Maritime and Structural Engineering, Department of Mechanical \\ Engineering, Technical University of Denmark, Nils Koppels Allé, Bygn. 403, 2800 \\ Kgs.Lyngby,Denmark.ngja@mek.dtu.dk,jf@mek.dtu.dk
}

\begin{abstract}
The free surface simulation of breaking waves is studied using a combination of VOF and RANS closures. Further, a numerical model for the detailed study of sediment transport and morphological development is presented. In the present study it is applied to the case of sediment transport in the surf zone. The temporal change of a cross shore beach profile under both regular and bichromatic waves is considered. The dependency on the morphological time scale on the regularity of the incident waves is discussed. The feedback onto the hydrodynamics due to a changing bed level is discussed in the case of regular waves.
\end{abstract}

\section{Introduction}

Formation of breaker bars are usually explained by shoreward sediment transport seaward of the point of breaking due to streaming, wave skewness and wave asymmetry (a recent summery is given by Fuhrman et al. 2009). Shoreward of the break point sediment is transported seaward by undertow. By modelling these two features it is possible to model the formation of breaker bars. Usually the detailed flow pictures in the transition zone in between shoreand seaward sediment transport in not accounted for in this description. To include this is the scope of the present paper in order to improve the understanding of the mechanics of breaker bars.

The detailed behaviour in the transition zone is described by adopting a free surface method coupled with the Reynolds Averaged Navier-Stokes equations with an appropriate turbulence closure. This is frequently applied when limited to the study of the hydrodynamics (e.g. Lin and Liu, 1998). However, few studies have been extended to describe the sediment transport, suspended transport in particular. These studies are to the authors' knowledge limited to those by Christensen et al. (2000) and Ontowirjo and Mano (2008, 2009), where the latter as the only to present considers the morphological development of a cross-shore beach profile. The details in Ontowirjo and Mano (2009), however, are scarce and no details on the coupling between hydrodynamics and bed movement is revealed. 
In this work, a full coupling between the hydrodynamics including wave breaking and the resulting sediment transport and morphological response is introduced. Further the interim results from a cross-shore beach profile development of an initially plane beach profile is considered under a regular and a bi-chromatic wave train.

\section{Model Description}

The numerical method is developed in the framework of OpenFOAM ${ }^{\circledR}$. It consists of three major parts, namely (i) a solution to the Reynolds Averaged Navier-Stokes equations including surface capturing using a VOF-technique very similar to that of Rusche (2002), chap. 4. The turbulence closure is a highReynolds number version of the $k-\omega$ turbulence model, (ii) a simulation of the sediment transport (both bed load and suspended load) and (iii) a morphological updating routine. Details on (i)-(iii) can be found in Jacobsen (2011). Regarding (ii) the bed load formulation follows Engelund and Fredsøe (1976) and the suspended sediment transport formulation is solved using an advection-diffusion equation (Fredsøe and Deigaard 1992) with a reference concentration concept following that of Engelund and Fredsøe (1976).

As a consequence of the two phases (air and water), it is not possible to apply explicit boundary conditions for suspended sediment transport at the water surface. However, the spatial variation of the fall velocity

$$
\mathbf{w}_{s}=\gamma \mathbf{w}_{s, 1}+(1-\gamma) \mathbf{w}_{s, 0}
$$

must be included into the conservation equation for the suspended volume concentration, $c$. This is accomplished by solving the following conservation equation

$$
\frac{\partial c}{\partial t}+\nabla \cdot\left(\mathbf{u}+\mathbf{w}_{s}\right) c-c\left(\mathbf{w}_{s, 1}-\mathbf{w}_{s, 0}\right) \cdot \nabla \gamma=\nabla \cdot v_{t} \nabla c
$$

Here $t$ is time, $\mathbf{u}$ and $\mathbf{w}_{\mathrm{s}}$ fluid and fall velocities respectively, $\mathbf{w}_{\mathrm{s}, 1}$ and $\mathbf{w}_{\mathrm{s}, 0}$ are fall velocities in water and air, $\gamma$ is the VOF colour function being 1 in water and 0 in air and $v_{t}$ is the eddy viscosity. This correction is found to be sufficient to avoid suspended sediment in the air phase. The formulation differs from that of Ontowirjo and Mano (2009), who simply multiply all terms by $\gamma$ in the noncorrected conservation equation. Eq. (2) is solved implicitly in time using a blended Crank-Nicholson and implicit Euler time stepping routine. 
The morphological change is found from the sediment continuity equation in the form

$$
\begin{aligned}
\frac{\partial h}{\partial t} & =-\frac{1}{1-e}\left[\nabla \cdot \mathbf{q}_{B}+E+D\right] \\
& \left.=-\frac{1}{1-e}\left[\nabla \cdot \mathbf{q}_{B}+v_{t} \frac{\partial c}{\partial n}+c_{B} \mid\left(\mathbf{w}_{s}+\mathbf{u}_{c}\right) \cdot \mathbf{n}\right]\right]
\end{aligned}
$$

Here $h$ is the bed level, $e$ the porosity, $\mathbf{q}_{B}$ the bed load vector, $n$ a coordinate perpendicular to the bed, $\mathbf{n}$ the bed unit normal vector, $c_{B}$ is the bed reference concentration, and $\mathbf{u}_{c}$ is the velocity over the boundary for suspended sediment. Eq. 3 is solved using a $3^{\text {rd }}$ order explicit Adam-Basforth time integration scheme, see Ferziger and Peric (2002), p. 139. To ensure stability the bed level change is filtered using the filter proposed by Jensen et al. (1999).

The addition of $\mathbf{u}_{c}$ in Eq. 3 is required, as the value of $c_{B}$ is given a distance of $2 d$ from the bed, where $d$ is the grain diameter. This implies that the solution to $c$ is found on a separate mesh and that there is a resulting advective flux over the bed boundary for suspended sediment, namely $c_{B} \mathbf{u}_{\mathrm{c}} \cdot \mathbf{n}$.

The morphological update is undertaken simultaneously with the solution of the equations of state by moving the computational mesh a distance $\Delta h$, being the distance found from Eq. 3 mapped into a vertical displacement. The mesh moving method is described in Jasak and Tukovic (2006).

\section{Test Case}

The numerical setup consists of an initially planar beach with a slope of 1:35. The water depth, $h$, is $0.4 \mathrm{~m}$ at the inlet. The beach consists of uniform sand with a diameter of $0.1 \mathrm{~mm}$ and a fall velocity of $0.0059 \mathrm{~m} / \mathrm{s}$. The fall velocity is $1.4 \mathrm{~m} / \mathrm{s}$ above the water surface. As a consequence of the separate mesh for suspended sediment, the near bed resolution needs to be less than $2 d$ resulting in large aspect ratios in the computational cells at the bed. At such aspect ratios the intersection of the bed and the water surface in the swash zone is not handled robustly in the VOF model. Therefore the planar beach is made horizontal in the swash zone with an initial water depth, $h$ ', of $1 \mathrm{~cm}$, see figure 1 . Barnett and Wang (1988) proved this to have only a minor effect on the beach profile development. $x$ and $y$ are the horizontal and vertical coordinates respectively. $x$ $=0 \mathrm{~m}$ where the water depth is $0.38 \mathrm{~m}$. 
Regular waves with a period of $2 \mathrm{~s}$ and wave height of $0.125 \mathrm{~m}$ is generated on the constant depth part of the domain. The generated waves are based on stream function theory, Rienecker and Fenton (1981).

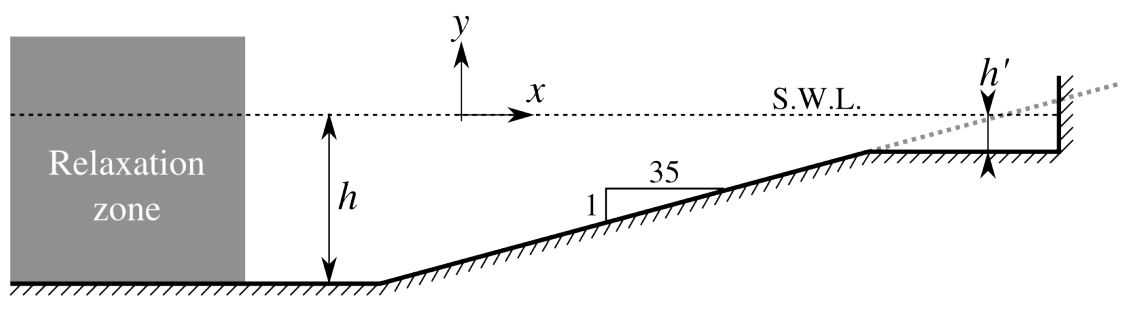

Fig. 1. Layout of the computational domain. The relaxation zone allows for momentum to leave the computational domain without causing unwanted reflection (Jacobsen, 2011).

The bichromatic waves are generated using a superposition of two Stokes second order waves. The waves have identical wave height such that $H_{r m s}$ is $0.125 \mathrm{~m}$. The period of the two waves is $1.66 \mathrm{~s}$ and $2 \mathrm{~s}$, respectively. The group period is found to be $10 \mathrm{~s}$ and the same holds for the repeat period of the wave train.

A relaxation zone is placed at the inlet and it is $4 \mathrm{~m}$ long. The necessity of a relaxation zone is discussed by Bradford (2000), where he found that it is not possible to simulate more than $O(10)$ wave periods, if the incident waves and the reflected waves/seaward directed mean flow are not separated. The method is described in details in Jacobsen (2011).

\section{Results}

\section{Bed Shear Stress Distribution on a Rigid Bed}

The bed shear stress over a rigid bed is considered initially to obtain a picture of the detailed bed shear stress distribution across the surf zone. In figure 2 the wave height variation across the surf zone is plotted and one break point can be indentified. This is further reflected in the variation of the Shields parameter $\left(\theta=\tau_{b} / \rho(s-1) g d\right)$, where it increases up to the point of breaking and then rapidly decreases. Here $\tau_{b}$ is the bed shear stress, $\rho$ is the density of water, $s$ is the relative density of the sediment and $g$ is the acceleration due to gravity. The minimum value is found around $x=7 \mathrm{~m}$. Figure 2 also shows the variation of $\theta^{3 / 2}$, which is a measure for the transport magnitude and direction. Outside the surf zone the standard deviation for the maximum and minimum is almost 0 whereas it is significant relative to the magnitude of $\theta^{3 / 2}$ inside the surf zone. 

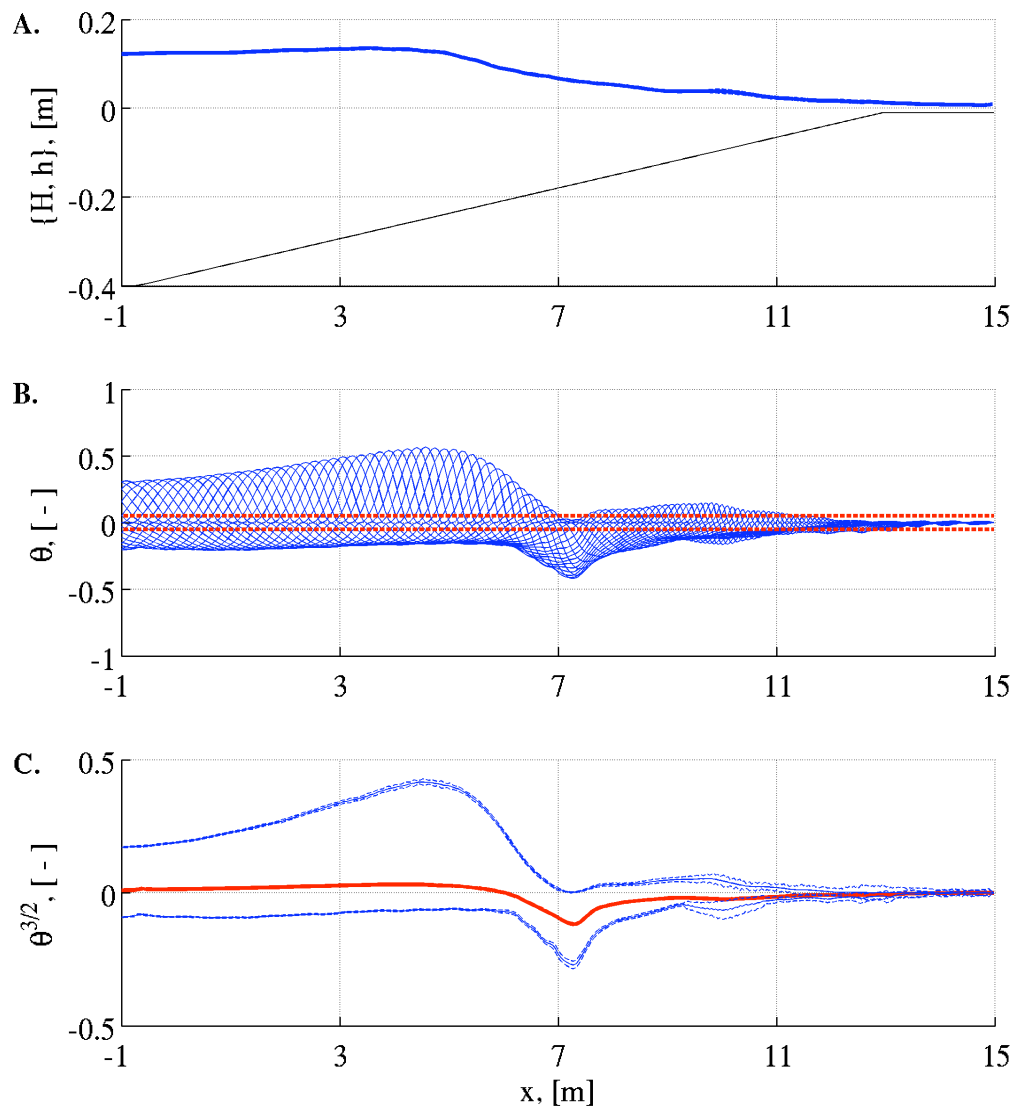

Fig. 2 Regular wave test on a rigid bed. Ensemble averaged from $200 \mathrm{~s}-400 \mathrm{~s}$. A: Wave height and beach profile. B: Ensemble average of the Shields parameter for 20 phases. Dashed bold lines at the critical Shields parameter. C: Maximum, average and minimum values of $\theta^{3 / 2}$. Dashed lines around maximum and minimum are offset by the standard deviation.

In figure 3 the same data is plotted for bichromatic waves where the ensemble average is taken over $10 \mathrm{~s}$. The gradients in $\theta^{3 / 2}$ are much less pronounced when considering them on a time-averaged scale. In the upper panel the height of the induced infra-gravity motion is included. It is seen that the wave amplitude to the right of the flume is mostly due to the long-wave standing pattern. The wave height is defined as the difference between the maximum and minimum of the $10 \mathrm{~s}$ ensemble averaged surface elevation. The period of the infra-gravity wave is $10 \mathrm{~s}$ and its length on the horizontal part fits the wavelength found from the 
linear dispersion relation. The time scale for the bar development can be expected to be longer in the case of bichromatic waves. Further, an active "swash" zone is to be expected, as the smaller waves in the wave group are allowed to propagate farther shoreward.
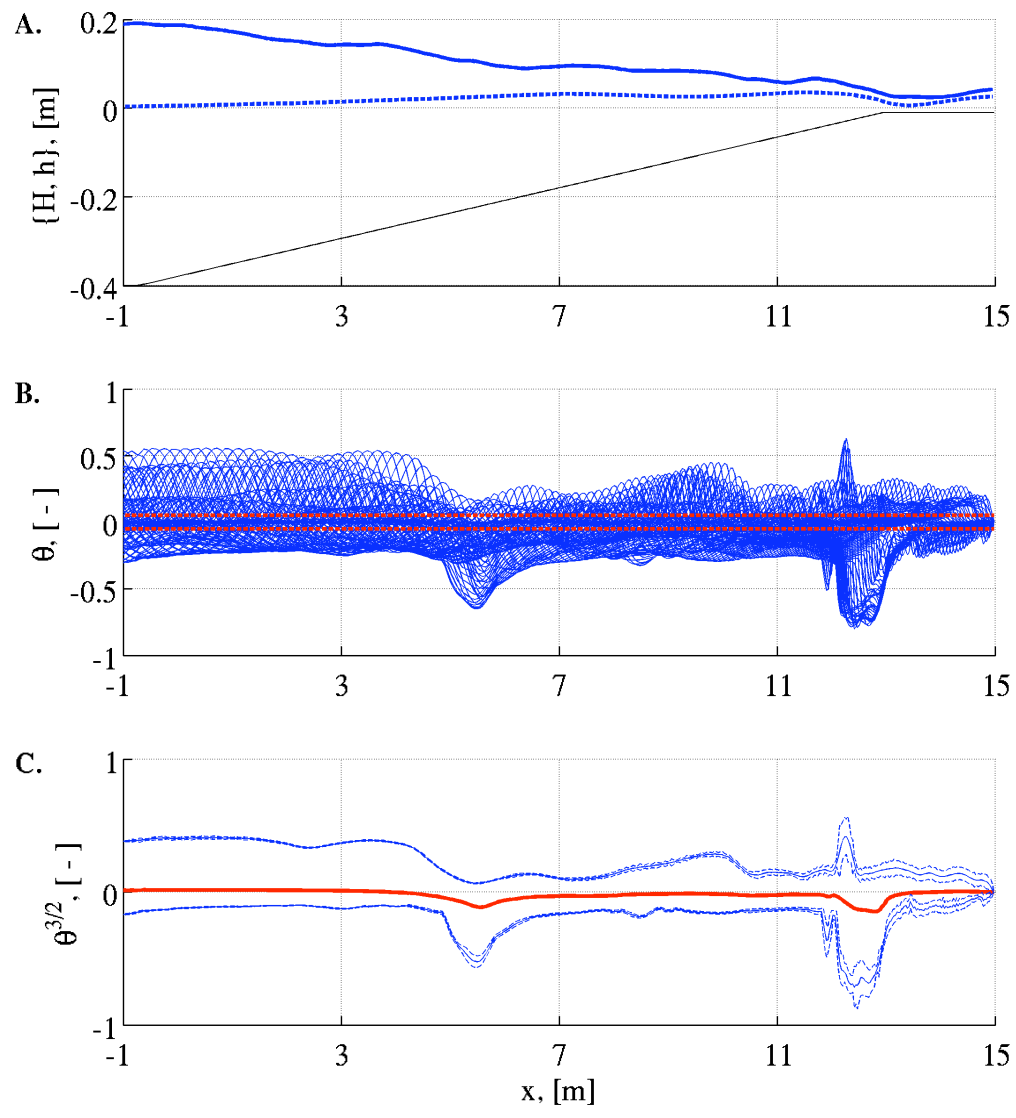

Fig. 3. Bichromatic wave test on a rigid bed. Ensemble averaged from $200 \mathrm{~s}-400 \mathrm{~s}$. A: Wave height and beach profile. B: Ensemble average of the Shields parameter for 100 phases. Dashed bold lines at the critical Shields parameter. C: Maximum, average and minimum values of $\theta^{3 / 2}$. Dashed lines around maximum and minimum are offset by the standard deviation. 


\section{Development of Beach Profile}

The development of the beach profile is considered firstly by plotting the profile at different times. This is done in figure 4 for regular waves and in figure 5 for bichromatic waves.
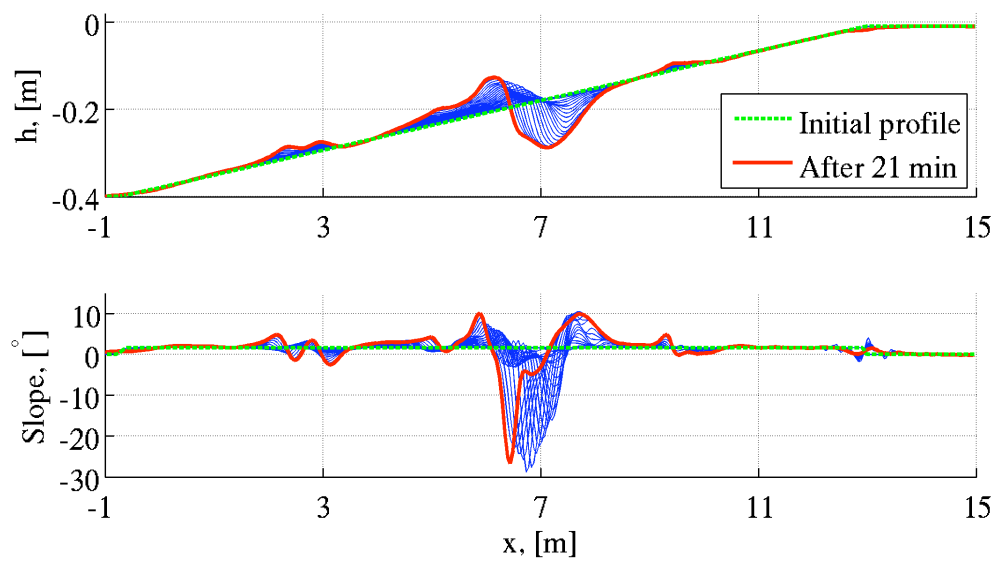

Fig. 4. Temporal development of the beach profile and beach slope for regular waves. There is $50 \mathrm{~s}$ between each line. Latest time is $1250 \mathrm{~s}$.
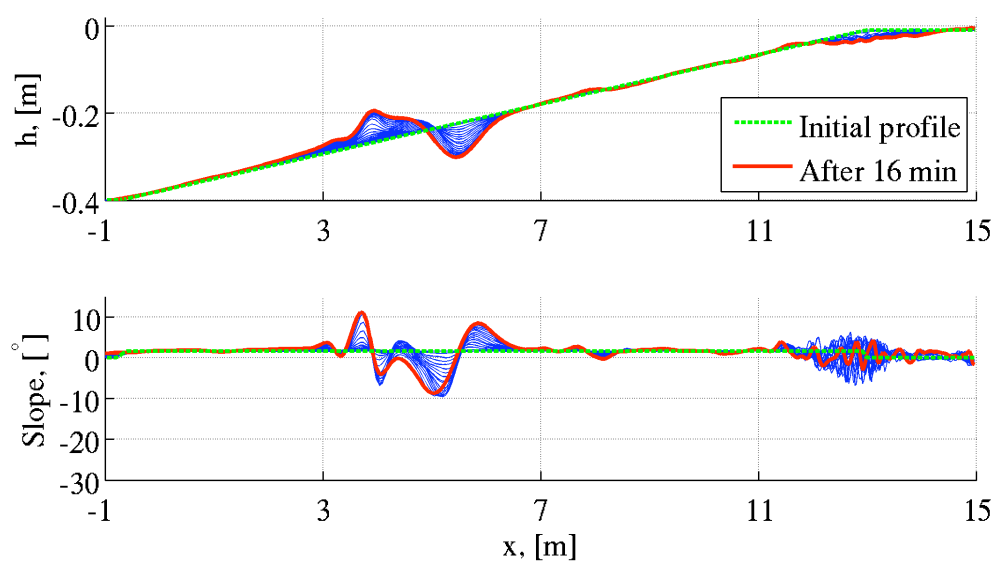

Fig. 5. Temporal development of the beach profile and beach slope for bichromatic waves. There is $50 \mathrm{~s}$ between each line. Latest time is $950 \mathrm{~s}$. 
These figures clearly show that the time scale for the regular waves is shorter than for bichromatic waves. Further it is seen that initially all morphological change occurs around $x=7 \mathrm{~m}$ but no morphological change occurs shoreward of this point. This is not the case for bichromatic waves, where pronounced erosion takes place in the "swash" zone. The hump at $x=9 \mathrm{~m}$ for regular waves appears late in the development (see also figure 6).

In the case of bichromatic waves the bar is located farther seaward because the largest breaking wave breaks earlier. In addition, the slope of the profile is much more gentle than in the case of regular waves. This is anticipated based on the Shield parameter distribution as depicted in figures 2 and 3 but also through a consideration of the physical process. Because regular waves repeatedly break at the same location, the same spatial location is only subject to either erosion or deposition (roughly speaking), whereas in irregular waves the variability of the break point spread the locations of both erosion and deposition over a larger segment of the coastal profile, thus smoothing the resulting cross shore profile.

Generally the process appears to be dominated by a trough erosion and a subsequent settling of the eroded sediment seaward of the trough. A comparison between the regular and bichromatic wave cases is seen in figures 6 and 7. Both show a faster decrease in trough level relative to the increase crest level. Further the bar crest is seen to propagate seaward while the trough is more static, which results in an increase of trough width. Additionally a complex merging of multiple crests and troughs is found in both cases. For bichromatic waves a crest shoreward of the break point is identified earlier than for regular waves. This is a consequence of the time variation in the wave train.

The magnitude of the bed slopes and the overall qualitative appearance bear resemblance to the experimental data by Dally (1987).

\section{Feedback on the Hydrodynamics}

The feedback on the hydrodynamics is considered through the temporal variation of the wave height for the case of regular waves. The initial trough is created at $x=7 \mathrm{~m}$, and the bar propagates seaward after the initial stage of the formation. The wave height at this location is depicted in figure 8 together with a set of cross shore profiles. It is seen that the wave height steadily decreases until $t=950 \mathrm{~s}$ suggesting that the breaking process is more and more evolved as the breaker bar propagates seaward. At $t=950 \mathrm{~s}$ the wave height increases rapidly and levels out at around $H=0.06 \mathrm{~m}$. The increase in wave height is due to a regeneration of propagating and non-breaking waves shoreward of the bar in the trough. 

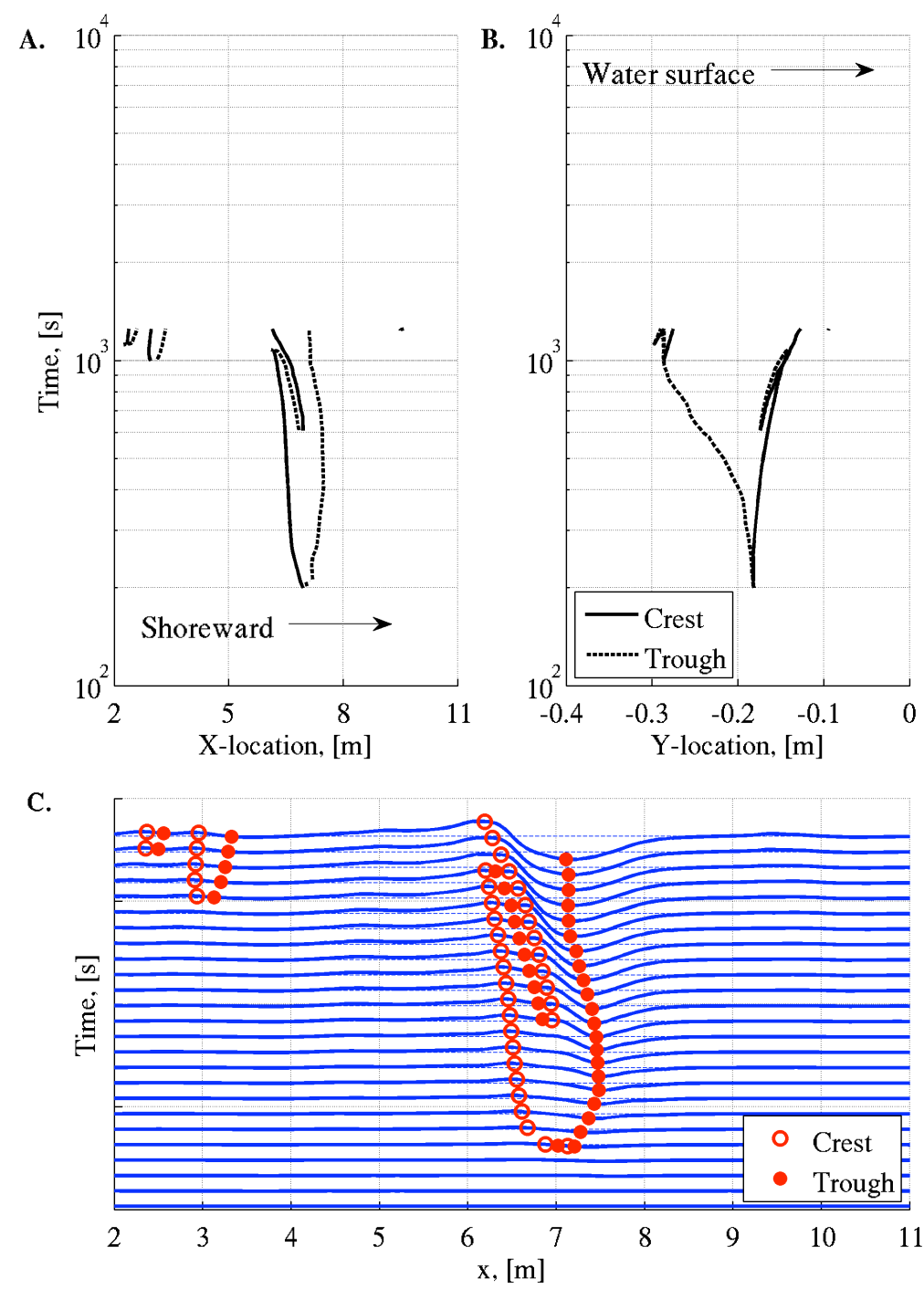

Fig. 6. Morphological development for regular waves. A: The location of the crests and troughs in the cross shore direction over time. B: The location in the crest and trough levels over time. C: Time stack of the bed level subtracted the initial profile. Full line is the profile and the dashed line is the reference level. There is $50 \mathrm{~s}$ between each line. 

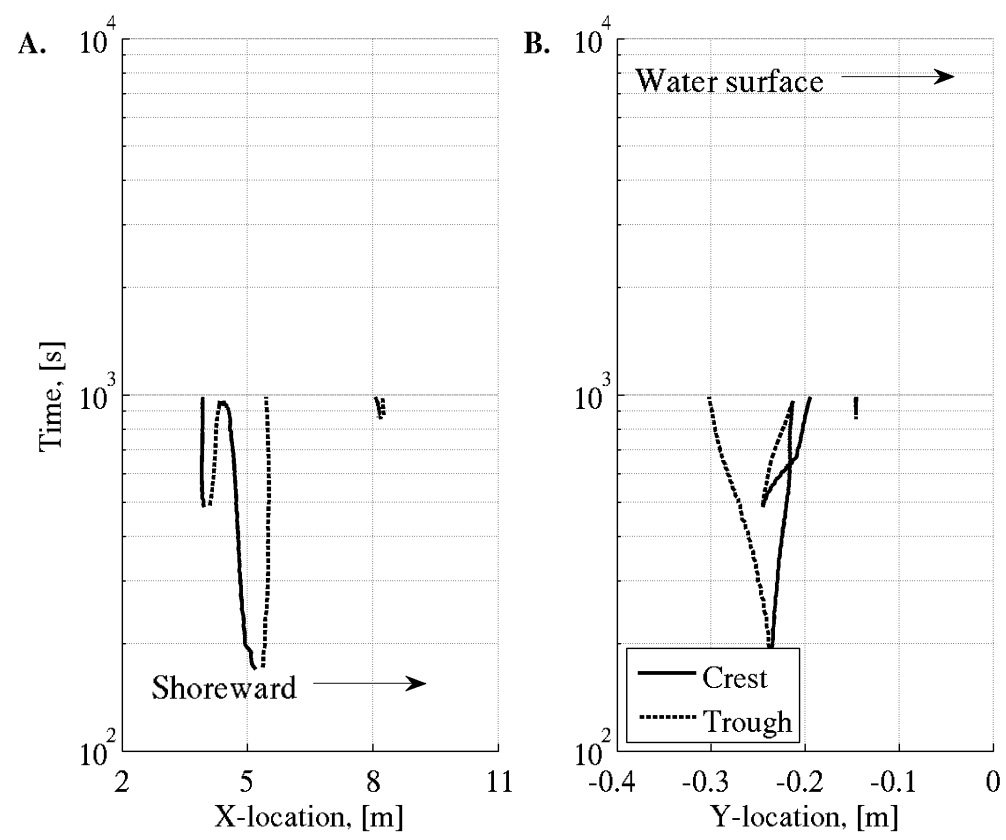

C.

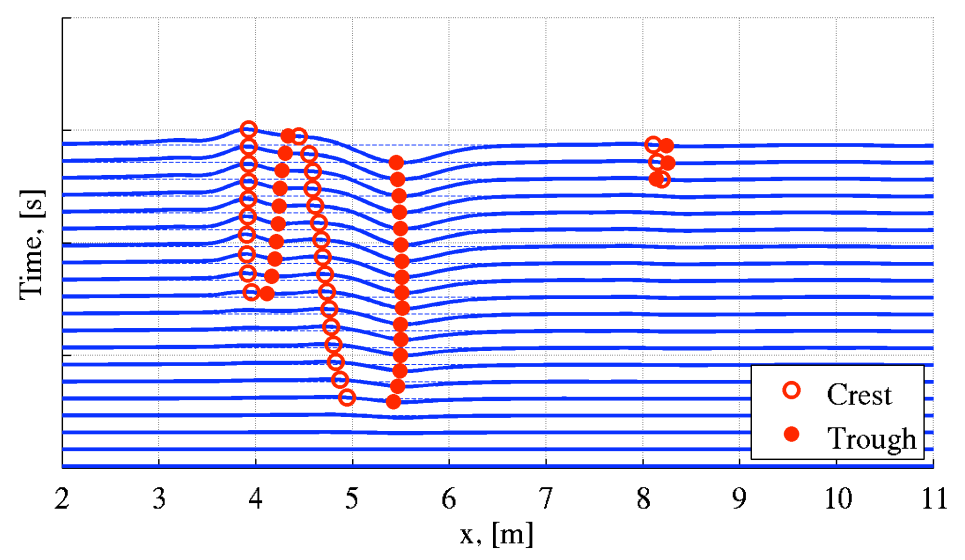

Fig. 7. Morphological development for bichromatic waves. A: The location of the crests and troughs in the cross shore direction over time. B: The location in the crest and trough levels over time. C:

Time stack of the bed level subtracted the initial profile. Full line is the profile and the dashed line is the reference level. There is $50 \mathrm{~s}$ between each line. 
As discussed in the previous section the hump shoreward develops late for regular waves. This is related to the regeneration of waves in the trough, which can then propagate shoreward and sustain an erosion/deposition process.
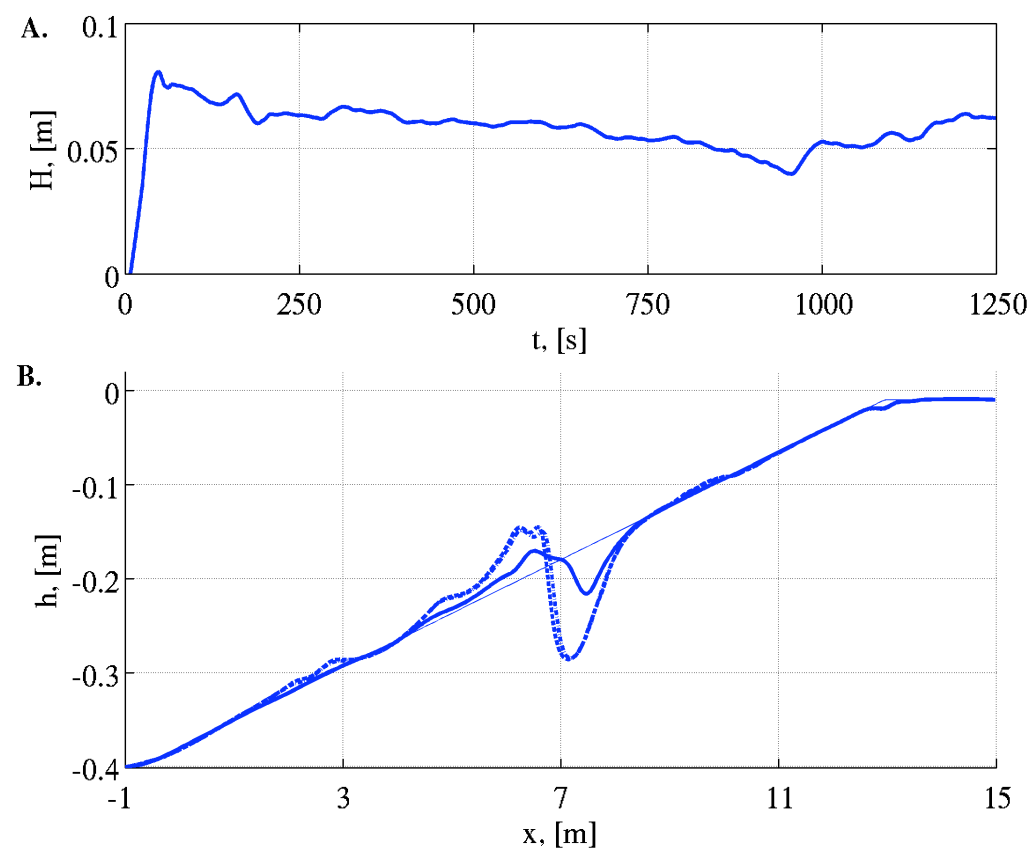

Fig. 8. A. Wave height variation at $x=7 \mathrm{~m}$. B. A set of cross shore profiles. Thin line at $t=0 \mathrm{~s}$. Wide line at $t=500 \mathrm{~s}$. Dash-dotted line at $t=950 \mathrm{~s}$. Dashed line at $t=1000 \mathrm{~s}$.

\section{Conclusion}

A detailed model is outlined for the computation of the flow over a bar and its implications on sediment transport and morphological response. This model has been applied to the complex processes in the surf zone to study the formation of breaker bars. It is seen that the formation process is an erosive process with an eroding trough and a subsequent deposition of eroded material seaward. The time scale for the formation process is seen to depend of the amount of regularity of the incident waves. An increase in regularity results in a decrease in the time scale. Regular waves are correctly (qualitatively) found to regenerate in the trough and break again shoreward to sustain an erosion/deposition sequence resulting in a new perturbation to the initial profile. For bichromatic waves the entire profile is subject to morphological change, however, most pronounced around the most seaward breaking wave and in the "swash" zone. 


\section{Acknowledgements}

We would like to thank Jacob H. Jensen, Kasper H. Kærgaard, and Ole Lindberg for fruitful discussions with respect to the development and formulation of the morphological module.

\section{References}

Barnet, M.R., and Wang, H. (1988). "Effects of a Vertical Seawall on Profile Response," Proceedings of the $21^{\text {st }}$ International Conference on Coastal Engineering, II, 1493-1507.

Bradford, S.F. (2000). "Numerical simulation of surf zone dynamics," Journal of Waterway, Port, Coastal and Ocean Engineering - ASCE, 126(1), 1-13

Christensen, E.D., Jensen, J.H., and Mayer, S. (2000). "Sediment Transport under Breaking Waves," Proceedings of the $27^{\text {th }}$ International Conference on Coastal Engineering, III, 2467-2480

Dally, W.R. (1987). "Longshore bar formation - surf beat or undertow?," Coastal Sediments '87, Proceedings of a Specialty Conference on Advances in Understanding of Coastal Sediment Processes, 1, 71-87.

Engelund, F., and Fredsøe, J. (1976). "Sediment Transport Model for Straight Alluvial Channels," Nordic Hydrology, 7(5), 293-306.

Ferziger, J.H., and Peric, M (2002). "Computational Methods for Fluid Dynamics." Springer Verlag, $3^{\text {rd }}$ edition.

Fredsøe, J., and Deigaard, R. (1992). "Mechanics of Coastal Sediment Transport," volume 3 of Advanced Series on Ocean Engineering. World Scientific, $1^{\text {st }}$ edition.

Fuhrman, D.R., Fredsøe, J., and Sumer, B.M. (2009). "Bed slope effects on turbulent wave boundary layers: 2 . Comparison with skewness, asymmetry, and other effects," Journal of Geophysical Research - Oceans, 114, article no. $\mathrm{C} 03024$.

Jacobsen, N.G. (2011). Ph.D. thesis. Coastal, Maritime and Structural Engineering, Department of Mechanical Engineering, Technical University of Denmark. 
Jasak, H., and Tukovic, Z. (2006). "Automatic Mesh Motion for the Unstructured Finite Volume Method," Transactions of FAMENA, 30(2), $1-20$.

Jensen, J.H., Madsen, E.O., and Fredsøe, J. (1999). "Oblique flow over dredged channels. II: Sediment transport and morphology," Journal of Hydraulic Engineering - ASCE, 125(11), 1190-1198.

Lin, P.Z., and Liu, P.L.F. (1998). "A numerical study of breaking waves in the surf zone," Journal of Fluid Mechanics, 359, 239-264

Ontowirjo, B., and Mano. A. (2008). “A Turbulent and Suspended Sediment Transport Model for Plunging Breakers," Coastal Engineering Journal, 50(3), 349-367.

Ontowirjo, B., and Mano. A. (2009). "Examination of Unified Sediment Transport and Cross Shore Morphology Model," Advances in Water Resources and Hydraulic Engineering, 1-6, 1272-1276.

Rienecker, M.M., and Fenton, J.D. (1981). “A Fourier Approximation Method for Steady Water-Waves,” Journal of Fluid Mechanics, 104, 119-137.

Rusche, H. (2002). "Computational Fluid Dynamics of Dispersed Two-Phase Flows at High Phase Fractions," Ph.D. thesis. Imperial College of Science, Technology and Medicine. 